SHORT REPORT

\title{
Immunoadsorption inferior to plasma exchange in a patient with chronic inflammatory demyelinating polyradiculoneuropathy
}

\author{
R D M Hadden, S Bensa, M P T Lunn, R A C Hughes
}

J Neurol Neurosurg Psychiatry 2002;72:644-646

Staphylococcal protein A immunoadsorption and plasma exchange were compared for treating chronic inflammatory demyelinating polyradiculoneuropathy. In a single patient, plasma exchange had a more beneficial effect than immunoadsorption on clinical outcome measures. Serum IgM antibody activity to peripheral nerve fell significantly following plasma exchange. Serum $\lg M$ and $\lg A$ fell more and lgG less after plasma exchange than after immunoadsorption. The superior efficacy of plasma exchange to immunoadsorption in this case may have been the result of removal of an $\lg M$ antibody.

S aphylococcal protein A immunoadsorption selectively removes immunoglobulins, especially $\operatorname{IgG}_{1}, \operatorname{IgG}_{2}$, and $\mathrm{IgG}_{4}$, by filtering plasma through columns containing staphylococcal protein A. Plasma exchange is of proven benefit in chronic inflammatory demyelinating polyradiculoneuropathy (CIDP),' but immunoadsorption has theoretical advantages. Immunoadsorption removes IgG more effectively than plasma exchange, and should have fewer adverse effects because it does not require the administration of albumin or donor plasma. The high binding affinity of IgG to staphylococcal protein A facilitates the immediate return of plasma back to the patient. For patients requiring repeated treatment, immunoadsorption may be cheaper than plasma exchange because the column can be reused. As immunoadsorption removes less IgM, it might predispose less to infection than plasma exchange. Successful use of immunoadsorption to remove IgG autoantibodies in renal disease has led to its use in Guillain-Barré syndrome, Fisher syndrome, myasthenia gravis, CIDP, and paraproteinaemic demyelinating neuropathy. ${ }^{2}$ We had the opportunity of comparing plasma exchange and immunoadsorption in a patient with CIDP.

\section{CASE REPORT}

A 39 year old $72 \mathrm{~kg}$ man had a 14 year history of definite CIDP supported by sural nerve biopsy. He was disabled by a severe sensory ataxia and action tremor and walked unsteadily with ankle supporting boots. Motor conduction velocities were reduced to $13 \mathrm{~m} / \mathrm{s}$ in the ulnar nerve and $14 \mathrm{~m} / \mathrm{s}$ in the median nerve, and sensory nerve potentials were absent. He had had a temporary response to oral prednisolone and failed to respond to azathioprine, cyclosporin, $\beta$ interferon, and intravenous immunoglobulin. His symptoms had stabilised while receiving twice monthly plasma exchange and $10 \mathrm{mg}$ prednisolone on alternate days for the past eight years. He usually noticed a symptomatic improvement five to 10 days after plasma exchange and a decline four to six days before his next treatment.

\section{METHODS}

\section{Interventions}

We compared immunoadsorption with plasma exchange in a crossover design. The patient received either plasma exchange or immunoadsorption every four weeks through the antecubital vein. It was planned that he should receive two to four months of each treatment (depending on response) and then change to the other treatment. Treatments were not randomised or blinded. The treatments actually received during the assessment period were four months of plasma exchange followed by four months of immunoadsorption, four months of plasma exchange, three months of immunoadsorption, and finally three months of plasma exchange. He continued to take prednisolone $10 \mathrm{mg}$ on alternate days.

Plasma exchange was performed on two days every four weeks, separated by one day. Each exchange replaced three litres of plasma (about one plasma volume) with 2.5 litres of $4.5 \%$ human albumin and 0.5 litres of citrate, using a Cobe Spectra machine (Gambro, Sweden). Immunoadsorption used a Citem $10^{\circledast}$ machine (Excorim, Lund, Sweden) and two Immunosorba $^{\circledast}$ protein A columns (Excorim). The first four immunoadsorption treatments filtered approximately 8 litres of plasma on one day every four weeks. Because of the poor response, this was then altered to two immunoadsorption treatments (of 6 litres and 8 litres, two days apart) every four weeks to maximise IgG removal.

Table 1 Changes in clinical assessments over four weeks following each treatment

\begin{tabular}{llll}
\hline & $\begin{array}{l}\text { Plasma exchange } \\
(\mathbf{n}=11)\end{array}$ & $\begin{array}{l}\text { Immunoadsorption } \\
\text { mean }(\mathrm{n}=7)\end{array}$ & $\mathrm{p}$ Value \\
\hline Task sum score* & $1(-1$ to 3$)$ & $-1(-3$ to 1$)$ & 0.02 \\
$10 \mathrm{~m}$ walk $(\mathrm{s})$ & $-0.8(0.9)$ & $1.4(0.6)$ & 0.07 \\
Tremor: water remaining in cup $(\mathrm{ml})$ & $20(12)$ & $-12(10)$ & 0.05 \\
Nine hole peg test $(\mathrm{s})$ & $-4(4)$ & $5(5)$ & 0.2 \\
MRC sum score & $2(2)$ & $-2(2)$ & 0.09 \\
\hline
\end{tabular}

Values are mean (SEM) or * median (range). 


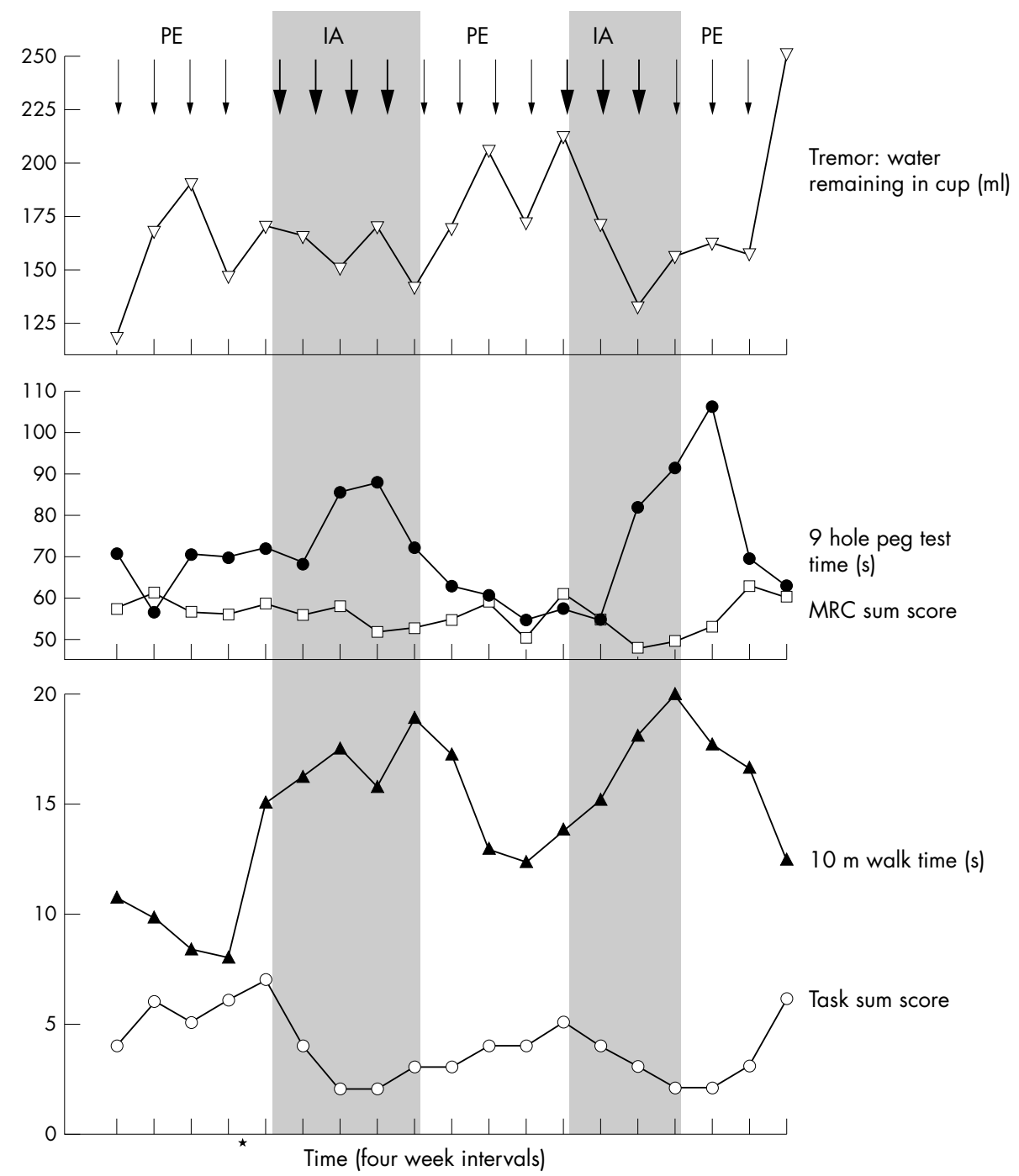

Figure 1 Clinical assessments were done immediately before each treatment at four week intervals. Most clinical outcomes worsened after immunoadsorption (IA, large arrows and shading) and improved after plasma exchange (PE, small arrows). Improvement is upwards for assessments with empty symbols, downwards for black filled symbols. The interval between the fourth PE and first IA was six weeks owing to Christmas holidays, resulting in unexpected worsening of the 10 metre walk time.

\section{Assessments}

Clinical assessments were done immediately before and then weekly following each treatment. They included 10 metre walk time, nine hole peg test time, MRC sum score, a "task sum score" (four simple tasks, chosen by the patient, that initially he could not quite do, and five that he could do with difficulty; scoring 1 for each task done), and a "water spilling test" as a measure of tremor (millilitres of water remaining in an initially full $250 \mathrm{ml}$ cup held in the right hand for $10 \mathrm{sec}-$ onds). Serum IgG, IgM, and IgA concentrations were measured before and immediately after each treatment.

The effect of each treatment was defined as the change in each outcome measure over the following four weeks- that is, the difference in value from immediately before each course of treatment to immediately before the next course of treatment. For each outcome measure, the mean effect from all plasma exchange treatments was compared with the mean effect from all immunoadsorption treatments by unpaired $t$ tests for parametric data and the Mann-Whitney U test for ordinal data.

\section{Serum antibody activity}

Antibodies to whole human peripheral myelin were measured by enzyme linked immunosorbent assay (ELISA). Peripheral myelin was prepared by standard methods ${ }^{3}$ from human cauda equina, obtained from a patient who had died of non-neurological causes. Microtitre plate wells were coated with $1 \mu \mathrm{g}$ of human peripheral myelin protein in $50 \mu \mathrm{l}$ of $1 \%$ methylglyoxal $(\mathrm{pH} 8)$ at $37^{\circ} \mathrm{C}$ and then blocked with $1 \%$ bovine serum albumin in phosphate buffered saline (BSAPBS). Sera were diluted 1:200 in 1\% BSA-PBS and incubated in wells overnight at $4^{\circ} \mathrm{C}$. Immunoglobulin class and subclass activities were detected by the addition of specific secondary antibodies (mouse antihuman $\operatorname{IgG}_{1}, \operatorname{IgG}_{2}, \mathrm{IgG}_{3}$, or $\operatorname{IgG}_{4}$ (The Binding Site, Birmingham, UK) or rabbit antihuman IgM or IgA (Dako A/S, Glostrup, Denmark)) at 1:500. Optical densities were measured after alkaline phosphatase development. Normal sera were included as controls.

Antibodies to myelin proteins were measured by western immunoblotting. ${ }^{4}$ In brief, samples containing $40 \mu \mathrm{g}$ total protein were fractionated by $10 \%$ SDS-PAGE and transferred to a polyvinylidine fluoride membrane by semi-dry transfer. Sera were diluted 1:500 and incubated with membranes overnight at $4^{\circ} \mathrm{C}$. Alkaline phosphatase conjugated antihuman IgG or IgM antibodies were added at 1:2500 dilution and detected with CDP-Star chemiluminescence (NEN Inc, Boston, Massachusetts, USA). 
Antibodies to gangliosides were sought by thin layer chromatography immuno-overlay. ${ }^{5}$ Whole ganglioside extracts of human cauda equina or ovine brain were separated by high performance thin layer chromatography in chloroform:methanol:0.02\% $\mathrm{CaCl}_{2}$ (60:40:8). Sera were overlaid at $1: 200$ and detected with rabbit antihuman IgG or IgM secondary antibodies (1:250; Dako) and then ${ }^{125} \mathrm{I}$ labelled donkey antirabbit IgG (1:250; Dako).

\section{RESULTS}

Immunoadsorption was significantly worse than plasma exchange on two objective outcome assessments-the task sum score and the water spilling test-and there was a tendency for immunoadsorption to be worse than plasma exchange on the other assessments (table 1, fig 1). The patient felt subjectively that all his symptoms gradually worsened following immunoadsorption and improved following plasma exchange.

Serum IgM concentrations were reduced more effectively by plasma exchange (by 71 (3)\%) (mean (SEM)) than by immunoadsorption (by 54 (3)\%, p = 0.05). IgA concentrations were also reduced more effectively by plasma exchange (by $69(2) \%$ ) than by immunoadsorption (by 42 (3)\%, $\mathrm{p}=0.008)$. Conversely, IgG concentrations were reduced slightly less effectively by plasma exchange (by $71(2) \%)$ than by immunoadsorption (by 84 (3)\%, NS).

IgM antibody activity against whole human peripheral myelin by ELISA was greater in the patient's serum before plasma exchange than in normal control sera. No significant antimyelin activity was detected by ELISA in any IgG subclass or IgA. Western immunoblotting of pretreatment sera detected IgM and IgG antibodies against a $36 \mathrm{kDa}$ myelin protein. No IgG, IgM, or IgA antibodies to gangliosides were detected. Two hours after plasma exchange, IgM antimyelin activity by ELISA was reduced by $22 \%$ compared with pre-plasma exchange values $(p=0.05)$ but there was no significant change in IgG or IgA antinerve activity.

\section{DISCUSSION}

We report the first direct prospective comparison of plasma exchange and immunoadsorption in a patient with CIDP, and show that plasma exchange had a greater clinical effect. This difference was significant for measures of tremor and functional tasks. The worsening during immunoadsorption presumably reflected withdrawal of plasma exchange. A likely explanation was the greater reduction by plasma exchange than by immunoadsorption of total IgM concentration, with a reduction by plasma exchange of the activity of an IgM antibody to peripheral nerve myelin. These results argue for a pathogenic role for an $\operatorname{IgM}$ antibody in this patient, although the antibody detected to a $36 \mathrm{kDa}$ peripheral myelin protein is only one of a number of possible candidates. Antibodies to a 36 $\mathrm{kDa}$ protein, probably related to $\mathrm{P} 0$, have been described in $5 \%$ of patients with $\mathrm{CIDP}^{4}$ and in 39\% of patients with amyotrophic lateral sclerosis, ${ }^{6}$ as well as in some patients with other neuropathies. An alternative reason for the greater benefit from plasma exchange is that it might remove complement factors and proinflammatory cytokines more effectively than immunoadsorption, although concentrations of these would probably rise again within days.

As CIDP is a heterogeneous condition, other cases probably have a different pathogenesis. A small proportion of CIDP sera have IgG or IgM antibodies to various proteins and glycolipids in peripheral myelin (reviewed by Meléndez-Vásquez et al ${ }^{4}$ ). In a study of 12 patients with CIDP, four had an IgG antibody capable of inducing demyelination in rats. ${ }^{7}$ Two of these sera contained IgM which bound to sciatic nerve sections but were not pathogenic in rats.

Previous reports of immunoadsorption in CIDP using various types of column have described beneficial responses in six patients, although none was randomised or controlled. ${ }^{8-11}$ In the only report comparing immunoadsorption with plasma exchange in a single patient, the authors expressed the opinion that their patient responded better to immunoadsorption than to plasma exchange, but this conclusion is weakened by the retrospective nature of the study without a crossover design, by the lack of data on the response to plasma exchange, and by the simultaneous use of varying immunosuppressive agents. ${ }^{8}$ Another patient with CIDP did not respond to immunoadsorption. ${ }^{12}$

In the present study, IgG was removed more effectively by immunoadsorption than by plasma exchange, as expected from the characteristics of protein A. No IgG anti-peripheral nerve antibodies were detected by ELISA, but IgG did bind to the same $36 \mathrm{kDa}$ protein to which IgM bound on western immunoblotting. IgG and IgM may differ in their recognition of the same antigen presented in different contexts. A previous study showed that plasma exchange reduced total IgG, IgM, and IgA concentrations and antibodies to gangliosides more effectively than tryptophan-immobilised immunoadsorption in GuillainBarré syndrome and Miller Fisher syndrome, although staphylococcal protein A immunoadsorption was not tested. ${ }^{13}$

\section{ACKNOWLEDGEMENT}

We thank Excorim, Lund, Sweden, for kindly providing the immunoadsorption column and technical advice.

\section{Authors' affiliations}

R D M Hadden, S Bensa, M P T Lunn, R A C Hughes, Department of Neuroimmunology, Guy's King's and St Thomas' School of Medicine, London SE 1, UK

Correspondence to: Professor Richard Hughes, Department of Neuroimmunology, Guy's King's and St Thomas' School of Medicine, Hodgkin Building, Guy's Hospital, London SE I IUL, UK;

richard.a.hughes@kcl.ac.uk

Received 2 August 2001

In revised from 17 December 2001

Accepted 10 January 2002

\section{REFERENCES}

1 Hahn AF, Bolton CF, Pillay $N$, et al. Plasma exchange therapy in chronic inflammatory demyelinating polyneuropathy: a double-blind, sham-controlled, cross-over study. Brain 1996:119:1055-66.

2 Giörstrup P, Watt RM. Therapeutic protein A immunoadsorption: a review. Transfus Sci 1990;11:281-302

3 Norton WT, Poduslo SE. Myelination in rat brain: method of myelin isolation. J Neurochem 1973;21:749-57.

4 Meléndez-Vásquez C, Redford J, Choudhary PP, et al. Immunological investigation of chronic inflammatory demyelinating polyradiculoneuropathy. J Neuroimmunol 1997;73:124-34.

5 Lunn MPT, Johnson LA, Fromholt SE. High affinity anti-ganglioside lgG antibodies raised in complex ganglioside knockout mice: re-examination of GD l a localization. J Neurochem 2000;75:404-12.

6 Nobile-Orazio E, Manfredini E, Sgarzi M, et al. Serum lgG antibodies to a $35-\mathrm{kDa}$ PO-related glycoprotein in motor neuron disease. J Neuroimmunol 1994;53:143-51

7 Yan WX, Taylor J, Andrias-Kauba S, et al. Passive transfer of demyelination by serum or $\mathrm{lg} G$ from chronic inflammatory demyelinating polyneuropathy patients. Ann Neurol 2000;47:765-75.

8 Ullrich H, Mansouri-Taleghani B, Lackner KJ, et al. Chronic inflammatory demyelinating polyradiculoneuropathy: superiority of protein $A$ immunoadsorption over plasma exchange treatment. Transfus Sci 1998;19(suppl):S33-8.

9 Yamawaki T, Suzuki N. Can immunoadsorption plasmapheresis be used as the first choice therapy for neuroimmunological disorders? Therapeutic Apheresis 1997; 1:348-52.

10 Inoue A, Oguchi K, Iwahashi T, et al. Prominent effect of immunoadsorption plasmapheresis therapy in a patient with chronic inflammatory demyelinating polyneuropathy associated with hepatitis B infection. Therapeutic Apheresis 1998;2:305-7.

11 Kawakami T, Sekijima Y, Tokuda T, et al. A case of chronic inflammatory demyelinating polyradiculoneuropathy complicated by phrenic nerve palsy. Rinsho Shinkeigaku - Clin Neurol 1998; 38: 118-21.

12 Inoue A, Koh CS, Yahikozawa H, et al. A pathogenic study of chronic inflammatory demyelinating polyradiculoneuropathy in a patient with hepatitis B infection. Arerugi 1994;43:585-9.

13 Tagawa Y, Yuki N, Hirata K. Ability to remove immunoglobulins and anti-ganglioside antibodies by plasma exchange, double-filtration plasmapheresis and immunoadsorption. J Neurol Sci 1998;157:90-5. 